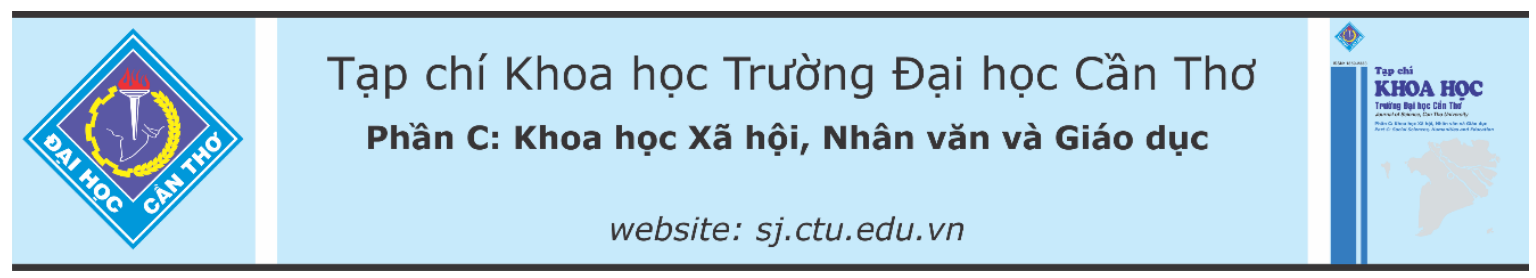

DOI:10.22144/ctu.jvn.2021.053

\title{
THỰC TRẠNG NGHIÊN CÚU BÀI HỌC VÀ NGHIÊN CÚU KHOA HỌC CỦA GIÁO VIỀ̃ TRUNG HỌC PHỔ THÔNG TẠI THÀNH PHỐ CẦN THƠ
}

\author{
Huỳnh Thị Thúy Diễm ${ }^{1 *}$ và Nguyễn Kỳ Tuấn Sơn ${ }^{2}$ \\ ${ }^{1}$ Khoa Su phạm, Truò̀ng Đại hoc Cần Tho' \\ ${ }^{2}$ Phòng Đào tạo, Trường Đại học Cần Tho \\ *Người chịu trách nhiệm về bài viết: Huỳnh Thị Thúy Diếm (email: httdiem@ctu.edu.vn)
}

\section{Thông tin chung:}

Ngày nhận bài: 08/10/2020

Ngày nhận bài sủa: 05/12/2020

Ngày duyệt đăng: 28/04/2021

\section{Title:}

Current status of lesson study and educational research by high school teachers in Can Tho city

\section{Tù khóa:}

Giáo viên trung học phổ thông, nghiên cưu bài học, nghiên cúu khoa hoc

\section{Keywords:}

High school teacher, lesson study, scientific research in educ

\begin{abstract}
This study provides information regarding the status quo, reasons, and solutions of applying lesson study (LS) into professional team meeting (PTM) and scientific research of education (SRE) among high-school teachers (HST) working in some schools in Can Tho City. The survey results, together with qualitative and quantitative analyses, applied to 431 HSTs indicate that LS has been implemented for more than 6 years, but the HSTs still have not got an adequate body of knowledge about LS, particularly its significance. Applying LS into the PTMs has not been conducted properly with regard to the essential principles from training, lesson planning, class participating, observing, and feedback. Some PTMs were not satisfied with the training about the format and content of LS theories as they expected much more profound knowledge, more practice, and more real-life experiences. Besides, the survey results showed that the LS activities, especially the SRE of the HSTs, were quite weak. Approximately $62.41 \%$ of the HSTs have never done any SRE; otherwise, they merely offered some experience initiatives. Therefore, $L S$ should be more proper training conducted by experts from the universities for HSTs.
\end{abstract}

\section{TÓM TẮT}

Nghiên cứu cung cấp thông tin về thực trạng, nguyên nhân, và giải pháp của việc áp dụng nghiên cứu bài học (NCBH) vào sinh hoạt tồ chuyên môn (SHTCM) và nghiên cúu khoa học giáo duc (NCKH) của giáo viên trung học phổ thông (GVTHPT) đang công tác tại một số truờng ở thành phố Cần Tho: Kết quả khảo sát và phân tích định tính cùng định luợng 431 GVTHPT cho thấy việc áp dụng $N C B H$ đã được thưc hiện đại trà hơn 6 năm, nhưng $N C B H$ vẫn chưa được GVTHPT hiểu đưng đắn và đầy đủ ý nghĩa khi thục hiện. Việc áp dụng NCBH vào SHTCM vẫn chua được GVTHPT thục hiện theo đúng quy trình và đúng nguyên tắc của NCBH tù khâu tập huấn, chuẩn bị giáo án cho đến khâu dư giờ, quan sát và phản hồi. Một số GVTHPT chưa hài lòng với việc tập huấn về hình thức và nội dung của lí thuyết NCBH và ho muốn được tập huấn về NCBH chuyên sâu, thực hành nhiều hơn với và có được nhũng trải nghiệm thực tế và hoạt động thực tế. Bên cạnh đó, kết quả khảo sát hoạt động NCKH đặc biệt là NCKHGD của GVTHPT rất yếu. Khoảng $62.41 \%$ GVTHPT chua tùng thưc hiện NCKHGD hoặc nếu có thì cũng chỉ thực hiện sáng kiến kinh nghiệm. Chính vì thế NCBH sẽ phải được tập huấn bài bản và trực tiếp tù những chuyên gia tù̀ trường đại học cho GVTHPT. 


\section{GIỚI THIÊUU}

Thuật ngữ "Nghiên cứu bài học" (lesson study/lesson research) theo tiếng Nhật (jugyo kenkyu) có nghĩa là nghiên cứu và cải tiến bài học cho đến khi nó tốt hơn (Lewis et al., 2006). Thuật ngữ này có nguồn gốc trong lịch sử giáo dục Nhật Bản, từ thời Meiji (1868 -1912), như một biện pháp để nâng cao năng lực nghề nghiệp của giáo viên thông qua nghiên cứu cải tiến các hoạt động dạy học ở từng bài học cụ thể.

Nghiên cứu bài học $(\mathrm{NCBH})$ có nguồn gốc từ Nhật Bản từ những năm 1870 (Makinae, 2010). Từ 1998, NCBH đã sử dụng rộng rãi ở Mỹ (Fernandez, 2002; Fernandez and Yoshida, 2004; Lewis et al., 2006; Stigler and Hiebert, 1999). Năm 1999, Hội thảo Nghiên cứu Khoa học và Toán học Quốc tế lần thứ ba đã đưa các tài liệu dân tộc học hiện có về nghiên cứu bài học đến với đông đảo công chúng (Stigler \& Hiebert, 1999). Trong khoảng thời gian chỉ hơn 4 năm, nghiên cứu bài học đã xuất hiện tại hơn 335 trường học Hoa Kỳ trên 32 tiểu bang và trở thành trọng tâm của hàng chục hội nghị, báo cáo và bài báo được xuất bản (Lewis et al., 2006), sau đó nhanh chóng mở rộng sang các quốc gia khác. Nghiên cứu bài học cũng đã triển khai ở các nước khác, bao gồm Singapore (Chong \& Kong, 2012; Lim et al., 2011; Tan-Chia et al., 2013), Hong Kong (Cheng, 2011), Indonesia (Suratno, 2012), Malaysia (Meng and Sam, 2011), Thái Lan (Inprasitha, 2011) và Việt Nam (Wheeler et al., 2011). Gần đây, các nhà giáo dục ở nhiều quốc gia đã bắt đầu học hỏi từ các chuyên gia giáo dục Nhật Bản cách phát triển văn hóa mới để thúc đẩy các cộng đồng học tập tại trường của họ. Cụ thể, các quốc gia như Hoa Kỳ, Trung Quốc, Indonesia, Singapore, Iran và Đức trong nô̂ lực chuyển đổi mô hình của Nhật Bản đã phát triển quan điểm riêng của họ về $\mathrm{NCBH}$ dựa trên văn hóa trường học, bối cảnh và nhu cầu giáo dục của quốc gia (Arani et al., 2010). Hiện nay, NCBH hầu như được áp dụng trên toàn thế giới nhằm phát triển nghề nghiệp chuyên môn của giáo viên (Reza et al., 2010; Chokshi \& Fernandez, 2004; Lewis, 2002a; Lewis et al., 2006; Lewis \& Tsuchida, 1998; Stigler \& Hiebert, 1999).

Ở Việt Nam, NCBH được giới thiệu lần đầu tiên từ năm 2004 đến 2007 thông qua dự án Cơ quan Hợp tác Quốc tế Nhật Bản (JICA). Dự án này được thực hiện tại 05 trường tiểu học ở tỉnh Bắc Giang (Saito et al., 2012). Mục tiêu của dự án là thay đổi văn hóa trường học để cải thiện sự hợp tác, quan hệ và chia sẻ giữa các giáo viên và xem như là phương thức để nâng cao chất lượng dạy và học. Kết quả việc áp dụng NCBH đối với dự án đầu tiên cho thấy $\mathrm{NCBH}$ giúp cải thiện sự hợp tác và phản hồi của các giáo viên về dạy và học toán ở trường Tiểu học và Trung học Cơ sở (Wheeler et al., 2011).

Dự án NCBH thứ hai được triển khai với môn Toán cấp 2 cho giáo viên ở 2 trường THCS Nguyễn Tri Phương tại Huế vào năm 2006 do Trần Vui, Trường Đại học Sư phạm Huế thực hiện, bằng nguồn tài trợ ban đầu từ Hợp tác kinh tế châu Á Thái Bình Dương (APEC). Ngoài ra, NCBH được thực hiện trong đào tạo giáo viên qua tập giảng và thực tập sư phạm ở Khoa Sư Phạm Kỹ thuật, Đại học Sư phạm Huế, do Nguyễn Duân thực hiện từ 2009. Kết quả nổi bật của những dự án là phát triển kỹ năng giao tiếp và xây dựng kiến thức cho học sinh đồng thời giúp giáo viên học cách mở rộng kiến thức trong giảng dạy (Tran Vui, 2013). Trước đó Tran Vui (2006) cũng khẳng định rằng $\mathrm{NCBH}$ thực sự là một công cụ đổi mới hiệu quả trong việc dạy và học toán ở trường trung học cơ sở.

Ngoài ra, vào năm 2007, với sự hỗ trợ của Trường Đại học Michigan thuộc Bang Michigan, Hoa Kỳ, cụ thể là Chris Wheeler của Đại học Michigan và Phùng Thị Nguyệt Hồng của trường Đại học Cần Thơ trực tiếp chỉ đạo, $\mathrm{NCBH}$ cũng được thực hiện lần đầu tiên ở tỉnh Hậu Giang thuộc vùng Đồng bằng Sông Cửu Long. Dự án này được thực hiện tại các trường tiểu học và trung học cơ sở với hai môn học, bao gồm Toán (lớp 7) và Địa lý (lớp 5). Sau đó, $\mathrm{NCBH}$ đã được mở rộng thử nghiệm trên 14 môn học khác nhau trong năm học 20082009 (Wheeler et al., 2011). Mục tiêu của dự án này nhấn mạnh cải thiện việc dạy và học. Kết quả dự án này mang lại là nâng cao kiến thức chuyên môn cũng như những kiến thức về nghiệp vụ sư phạm và cải thiện nhu cầu học tập về Địa lý và Toán học của giáo viên ở trường tiểu học và trung học cơ sở (Bui Lan Chi et al., 2008; Ho Thi Thu Ho et al., 2009).

Sau đó, NCBH được tiếp tục thực hiện trong đào tạo giáo viên ở Khoa Sư phạm ĐHCT đối với ngành Sư phạm Hóa học, Sư phạm Tiểu học và Sư Phạm Địa lý từ năm 2010 do Hồ Thị Thu Hồ và cộng tác viên thực hiện trong quá trình tập giảng của sinh viên Địa lý (Ho Thi Thu Ho et al., 2012). Những nghiên cứu trên đây đã chứng minh rõ ràng rằng áp dụng NCBH mang lại nhiều lợi ích cho giáo viên. Hầu hết các giáo viên tham gia vào các dự án này đều khẳng định rằng việc áp dụng $\mathrm{NCBH}$ mang lại phương pháp giảng dạy tích cực hơn, tạo mối quan hệ tốt giữa các giáo viên trong trường (Saito et al., 2008). Đặc biệt, áp dụng NCBH cũng giúp giáo viên thấy được mối liên hệ giữa lý thuyết và vận dụng 
những kiến thức lý thuyết để giải quyết các tình huống thực tế trong cuộc sống (Tran Vui, 2013). Các giáo viên tham gia dự án NCBH đã cải thiện các hoạt động dạy và học bằng cách sử dụng nhiều chiến thuật như sử dụng câu hỏi hiệu quả với phương tiện dạy học, kết hợp kiến thức sẵn có của học sinh để giúp các em xây dựng kiến thức mới (Bui Lan Chi et al., 2008; Ho Thi Thu Ho et al., 2008).

Chính vì những lợi ích của việc áp dụng NCBH, năm 2014, Bộ Giáo dục và Đào tạo (GD\&ĐT) Việt Nam đã ban hành hai công văn về việc sử dụng $\mathrm{NCBH}$ trong các buổi họp tổ chuyên môn ở trường từ Tiểu học đến cấp trung học phổ thông (Bộ Giáo dục và Đào tạo, 2014a, 2014b) nhằm nâng cao chất lượng dạy và học ở Việt Nam. Vì vậy, $\mathrm{NCBH}$ đã được áp dụng rộng rãi trên mọi đối tượng trong cả nước. Sau đó, ngày 6 tháng 9 năm 2014 Sở Giáo dục và Đào tạo Thành phố Cần Thơ đã ban hành công văn số 1680/SGDĐT-GDTrH hướng dẫn thực hiện nhiệm vụ Giáo dục trung học năm học 2014-2015 (Sở Giáo dục và Đào tạo, 2014). Việc thực hiện NCBH đã hơn 6 năm nhưng vẫn chưa được khảo sát hay tổng kết. Vì thế, nghiên cứu này nhằm tìm hiểu thực trạng hoạt động $\mathrm{NCBH}, \mathrm{NCKH}$ và các yếu tố ảnh hưởng đến áp dụng $\mathrm{NCBH}$ của các giáo viên THPT trong thành phố Cần Thơ. Đồng thời, đề xuất giải pháp nhằm áp dụng đúng đắn tiến trình $\mathrm{NCBH}$ để phát triển năng lực $\mathrm{NCKH}$ của giáo viên trung học phổ thông (GVTHPT).

\section{PHƯƠNG PHÁP VÀ PHƯỚG TIỆN NGHIÊN CÚU}

\subsection{Phương pháp nghiên cứu}

Nghiên cứu này được thực hiện theo mô hình nghiên cứu điều tra cắt ngang (crossestional survey) và phỏng vấn nhóm giáo viên với sự kết hợp của cả hai hình thức nghiên cứu định lượng và định tính (Cohen et al., 2007).

\subsection{Phương tiện và đối tượng nghiên cứu}

Phương tiện nghiên cứu trong đề tài này là phiếu điều tra và bảng câu hỏi phỏng vấn. Phiếu điều tra gồm ba phần: (1) phần thông tin chung của mẫu chọn, (2) phần khảo sát thực trạng áp dụng $\mathrm{NCBH}$ (chỉ tiêu cần khảo sát gồm: quan niệm về $\mathrm{NCBH}$, tập huấn $\mathrm{NCBH}$, vấn đề soạn giáo án, dạy thử nghiệm và quan sát, phản hồi góp ý, áp dụng $\mathrm{NCBH}$ sẽ phát triển năng lực gì cho GVTHPT) và (3) phần thông tin về NCKHGD (đã từng làm NCKHGD, những kỹ năng cần của người NCKHGD, những khó khăn và đề nghị khi làm $\mathrm{NCBH}$ và $\mathrm{NCKHGD).} \mathrm{Những} \mathrm{dạng}$ câu hỏi dùng trong phiếu điều tra của nghiên cứu này là những câu hỏi có không, câu hỏi lựa chọn, câu hỏi mở và câu hỏi dùng thang đo Likert scale (thang đo Likert là thang điểm năm (hoặc bảy) được sử dụng để cho phép cá nhân thể hiện mức độ họ đồng ý hoặc không đồng ý với một tuyên bố cụ thể) (Likert, 1932). Phiếu câu hỏi phỏng vấn được thiết kế dựa trên kết quả của bảng câu hỏi định lượng và tập trung vào thực trạng của việc áp dụng $\mathrm{NCBH}$ trong học tập và giảng dạy ở trường phổ thông. Phỏng vấn sâu theo nhóm được sử dụng để khảo sát việc tập huấn $\mathrm{NCBH}$, hiểu biết về $\mathrm{NCBH}$, việc thực hiện NCBH trong việc soạn giáo án, $\mathrm{NCBH}$ trong dự giờ và $\mathrm{NCBH}$ trong phản hồi. Phiếu điều tra của nghiên cứu được xây dựng theo các bước của chu trình NCBH (Clea Fernandez \& Yoshida, 2004; Lewis, 2000; Lewis, 2002b; Stigler \& Hiebert, 1999) và dựa trên hoàn cảnh thực tế áp dụng $\mathrm{NCBH}$ ở Việt Nam. Trước khi thu thập dữ liệu, bảng câu hỏi đã được tiến hành khảo sát thử trên 10 GVTHPT làm cơ sở điều chỉnh lại phiếu khảo sát. Sau đó, bảng câu hỏi được chuyển đến tất cả các GVTHPT tại Thành phố Cần Thơ, Việt Nam.

Dựa theo bảng xác định cỡ mẫu của Krejcie and Morgan (1970), số mẫu nghiên cứu trong đề tài này là 320. Tuy nhiên, trong hoàn cảnh thực tế, có 431 GVTHPT đã tham gia khảo sát bằng cách sử dụng phương pháp lấy mẫu thuận tiện (Cohen et al., 2007) từ một số trường trung học ở thành phố Cần Thơ. Sau cuộc khảo sát định lượng, có 40 GVTHPT đã được chọn để phỏng vấn nhóm (Cohen et al., 2007). Thời gian tiến hành khảo sát là tháng 9 năm 2019.

\subsection{Thu thập và xửa lí số liệu}

Dữ liệu định lượng được phân tích bằng thống kê mô tả và phần mềm SPSS để tính điểm trung bình, tần số, tỉ lệ phần trăm và độ lệch chuẩn (Trọng Hoàng \& Chu Nguyễn Mộng Ngọc, 2008). Dữ liệu định tính được phân tích bằng phương pháp nghiên cứu lý thuyết (grounded theory) phân tích, tổng hợp, so sánh, mã hóa và phân loại theo cùng một ý tưởng (Glase \& Strauss, 1967). Các kết quả định lượng và kết quả định tính được so sánh, tích hợp và diễn giải bằng mô hình hội tụ của tam giác.

\section{KẾT QUẢ THẢO LUẬN}

Có 431 giáo viên thuộc các trường THPT trong thành phố Cần Thơ đã tham gia trả lời phiếu khảo sát. Trong đó, có 164 nam chiếm $38,1 \%$ và $61,9 \%$ là nữ. Phân nửa các giáo viên tham gia khảo sát có thâm niên giảng dạy dưới 15 năm trong tổng số giáo viên được khảo sát. Phân nửa còn lại giáo viên tham gia khảo sát có thâm niên dạy học trên 15 năm, trong đó, số giáo viên có thâm niên trên 20 năm có tỉ lệ là $22,3 \%$. Điều này chứng tỏ đối tượng nghiên cứu đa 
dạng và có tay nghề tương đối cao và vững vàng. Ngoài ra, thành phần giáo viên tham gia nghiên cứu phân bố hầu hết các chuyên môn giảng dạy, trong đó, môn văn chiếm tỉ lệ $(14,39 \%)$ có số lượng giáo viên tham gia nhiều nhất và môn Vật lý -Tin học chiếm tỉ lệ ít nhất $(1,62 \%)$.

\subsection{Thực trạng về NCBH}

\subsubsection{Quan niệm của giáo viên về $N C B H$}

Theo lý thuyết về NCBH, mô hình này được thực hiện bởi nhóm giáo viên hợp tác cùng nhau, cùng nghiên cứu bài học giảng dạy thực tế trên lớp học thực tế. Các giáo viên này cùng nhau thiết kế giáo án của một bài học cụ thể nào đó, sau đó dạy thử nghiệm, dự giờ, quan sát cẩn thận quá trình học của học sinh, thảo luận, phản hồi, chỉnh sửa, giảng lại và chia sẻ những kết quả đã học được cho đồng nghiệp, để cho việc giảng dạy bài học đó ngày càng tốt hơn (Lewis, 2000, 2002b). NCBH cũng là một hình thức phát triển nghề nghiệp của giáo viên thông qua việc quan sát cẩn thận quá trình học của học sinh (nhất là những học sinh yếu hay học sinh cá biệt) để nâng cao chất lượng giảng dạy và cải thiện kêt quả học tập của học sinh (Lewis \& Tsuchida, 1998; Lieberman, 2009; Stigler \& Hiebert, 1999).

Như vậy, $\mathrm{NCBH}$ được thực hiện trên nhóm các giáo viên hợp tác cùng nhau và nghiên cứu một bài học thực tế theo quy trình: (1) thiết kế giáo án; (2) đại diện một giáo viên dạy thử nghiệm kết hợp với dự giờ quan sát của nhóm giáo viên đó về quá trình học tập của học sinh; (3) tiếp đến phản hồi, suy ngẫm về tiết dạy thử nghiệm đó; (4) sau đó cả nhóm giáo viên đó cùng chỉnh sửa lại giáo án vừa thực nghiệm và đại diện giáo viên khác trong nhóm giảng lại ở một lớp học khác. Tiến trình này lặp lại cho đến khi cả nhóm thấy rằng có một giáo án tôt hơn so với giáo án ban đầu; (5) cuối cùng chia sẻ lại tất cả những kinh nghiệm và những thành quả mà nhóm đạt được cho những đồng nghiệp khác để thúc đẩy quá trình dạy học ngày một chất lượng hơn.

\section{Bảng 1. Quan niệm của GVTHPT về NCBH}

\begin{tabular}{|c|c|c|c|c|}
\hline S1 & \multicolumn{2}{|l|}{ Nội dung } & & \\
\hline 1 & \multicolumn{2}{|c|}{$\begin{array}{l}\text { NCBH là một quá trình GV lên kế hoạch giao việc cho HS nghiên cứu } \\
\text { sau đó thu sản phẩm và nhận xét. }\end{array}$} & 254 & 8,9 \\
\hline 2 & \multicolumn{2}{|c|}{$\begin{array}{l}\text { NCBH là hình thức dạy học xem người học là “trọng tâm” giáo viên } \\
\text { chỉ có nhiệm vụ hướng dẫn. }\end{array}$} & 55 & 2,7 \\
\hline 3 & \multicolumn{2}{|c|}{$\begin{array}{l}\text { NCBH là một HĐ dạy học mà trong đó việc thực hiện là do sự hợp tác } \\
\text { của cả tồ "chuyên môn" có sự phân công nhiệm vụ̂ lần nhau giữa các } \\
\text { thành viên nhằm thực hiện một tiết dạy, xem hoạt động này tác động } \\
\text { đến học sinh như thế nào, giúp người học phát triển năng lực, sau đó } \\
\text { đánh giá và rút kinh nghiệm, điều chỉnh lại nội dung và phương pháp, } \\
\text { dạy lại, dự giờ, chỉnh sửa giáo án tốt hơn. }\end{array}$} & 57 & 3,2 \\
\hline 4 & \multicolumn{2}{|c|}{$\begin{array}{l}\text { Là hoạt động dạy học: thiêt kế kế hoạch dạy học, phân tích hoạt động } \\
\text { học của HS. Tìm ra những khó khăn mà học sinh gặp phải trong lúc } \\
\text { học. Từ đó rút kinh nghiệm và đưa ra biện pháp giải quyết nhằm hố trợ } \\
\text { GV trong việc nâng cao đánh giá kết quả học tập của HS. }\end{array}$} & 27 & 6,2 \\
\hline 5 & \multicolumn{2}{|c|}{$\begin{array}{l}\text { Là hoạt động nghiên cứu nội dung, phương pháp, mục tiêu, yêu cầu cần } \\
\text { đạt, cầu hỏi sử dụng nhằm phát triền tư duy học sinh. }\end{array}$} & 38 & 8,8 \\
\hline \multicolumn{3}{|l|}{ Tống cộn } & 431 & \\
\hline \multicolumn{2}{|r|}{ 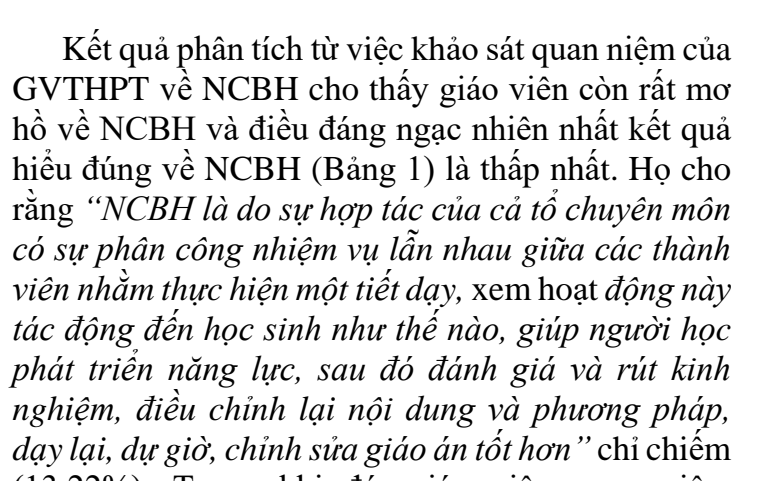 } & \multicolumn{3}{|c|}{ 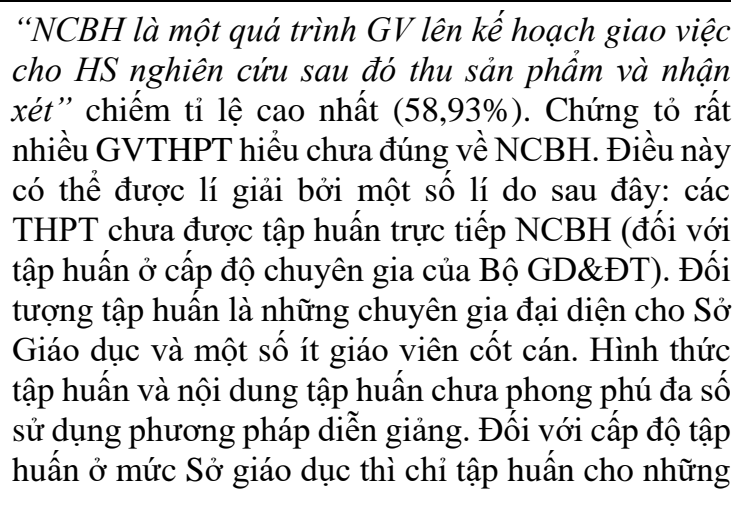 } \\
\hline
\end{tabular}


GVTHPT là tổ trưởng chuyên môn. Thông qua họp tổ chuyên môn các tổ trưởng này chia sẻ lại những hiểu biết của mình về NCBH cho đồng nghiệp. Thực tế thời gian tập huấn cho giáo viên những người trực tiếp thực hiện $\mathrm{NCBH}$ cũng không nhiều, và có những thắc mắc mà giáo viên đặt ra cũng chưa được giải thích thỏa đáng (Huynh Thị Thuy Diem and Thathong, 2017).

3.1.2. Các hoạt động liên quan đến NCBH cụ thể của giáo viên

\section{Về tập huấn nghiên cứu bài học}

Kết quả khảo sát về thực tế GVTHPT được tập huấn về $\mathrm{NCBH}$ cho thấy tỉ lệ $\mathrm{GV}$ được tập huấn trực tiếp từ chuyên gia của Bộ GD\&ĐT là $8,12 \%$, chiếm tỉ lệ thấp nhất. Phần còn lại đa số các GVTHPT được tập huấn từ tổ trưởng chuyên môn $(47,56 \%)$ cao nhất và chuyên viên của $S o ̛ ̉ ~ G D ~(44,32 \%)$. Và do đó các GVTHPT đề nghị khi tập huấn về NCBH:

- Cần có chuyen gia tập huấn và tập huấn trục tiếp rộng rãa đến tùng giáo viên để ai cũng hiểu và thực hiện cho hiệu quả. Vì nếu chi tập huấn cho cán bộ đại diện của truờng thì khi tập huấn lại rất khó tiếp thu tam sao thất bản, nhiều khi cán bộ đi tập huấn là giáo viên trẻ nên khi về chia sẻ lại không hết $\dot{y}$, hoăc sai ý và khi giáo viên có thắc mắc thì bản thân giáo viên đó không trả lời được nhất là cách phản hồi, nội dung phản hồi, cách soạn giáo án theo nhóm.

- Không hài lòng vì tập huấn chura kỹ, cần tập huấn chi tiết, cần có tiết giảng mẫu của người Việt Nam.

- Khi tập huấn toàn diễn giảng lý thuyết không có thực hành cho nên đề nghị khi tập huấn cần có một tiết thực hành dạy thư và áp dụng thực tế tình huống ở Việt Nam.

\section{Về quy trình NCBH}

Lựa chọn bài học để thực hiện NCBH và thực tế soạn giáo án
Theo lý thuyết NCBH thì bài học nghiên cứu nên chọn bài học khó dạy hoặc học sinh cảm thấy khó hiểu khi học. Thực tế, kết quả khảo sát thì NCBH thực hiện theo hình thức chủ đề do nhóm lựa chọn là $(44,08 \%)$ còn lựa chọn theo bài học $(55,92 \%)$. Bên cạnh đó, áp dụng NCBH dạy theo chủ đề mang đến nhiều phiền phức cho cả giáo viên và $\mathrm{HS}$ qua kết quả định tính sau đây: "Không hài lòng vì khi áp dụng NCBH phải dạy thêm buổi và thời gian dạy vì bao giờ cũng hơn một tiết hoc làm cho chán hoc. Điều này chứng tỏ giáo viên chưa hiểu hết ý nghĩa của việc lựa chọn bài học để thực hiện. NCBH là tận dụng chất xám của tập thể để làm sao cho từng bài dạy trên lớp (theo chương trình) ngày càng hiệu quả hơn do sự hợp tác của tất cả giáo viên trong tổ chuyên môn. Kết quả NCBH là tạo ra một giáo án tốt hơn so với ban đầu và phù hợp hơn với từng đối tượng học sinh, làm giảm sự khó khăn của học sinh khi tiếp thu kiến thức mới. Ngoài ra, $\mathrm{NCBH}$ là làm sao tìm ra phương pháp dạy học hiệu quả giúp cho HS nhận ra việc học trở nên nhẹ nhàng vui vẻ, thoải mái nhưng lại hiểu sâu và hiểu đúng nội dung kiến thức bài học hơn (Lewis, 2002).

Khi thực hiện giáo án thì nội dung quan trọng nhất mà thầy cô tập trung nhiều nhất là "phuơng pháp dạ hoc" $(65,4 \%)$ và thứ nhì là "nôi dung bài hoc" (52,7\%). Trong khi đó "nhũng khó khăn của học sinh khi học bài này" chiếm tỉ lệ thấp nhất $(21,3 \%)$. Kết quả này được trình bày ở Bảng 2 cho thây giáo viên vẫn theo suy nghĩ thông thường là làm sao tìm phương pháp dạy học tốt nhất dựa vào nội dung sẵn có và dựa vào niềm tin chủ quan của bản thân. Theo cách nghĩ của giáo viên, nếu dùng phương pháp này thì sẽ tốt cho học sinh. Tuy nhiên, giáo viên quên rằng việc tìm ra phương pháp dạy học hiệu quả nhất là từ những thực tế của học sinh, những khó khăn mà học sinh gặp phải trong khi học. Thực tế, theo chuyên gia giáo dục Lewis (2000), NCBH là phương pháp vận dụng để nâng cao hiệu quả dạy học thông qua quan sát thật cẩn thận quá trình học và làm việc của học sinh khi học (Lewis, 2002).

Bảng 2. Những vấn đề trong biên soạn giáo án được giáo viên quan tâm đến nhiều nhất

\begin{tabular}{clrrrr}
\hline \multirow{2}{*}{ STT } & \multirow{2}{*}{ Nội dung } & \multicolumn{2}{c}{ Có } & \multicolumn{3}{c}{ Không } \\
\cline { 3 - 5 } & Mục tiêu bài học & 196 & 45,5 & $\mathbf{n}$ & $\mathbf{\%}$ \\
\hline 1 & Nội dung bài học & 272 & 52,7 & 204 & 54,5 \\
2 & 282 & 65,4 & 149 & 34,3 \\
3 & Phương pháp dạy học & 247 & 57,3 & 184 & 42,7 \\
4 & Tổ chức dạy học & 182 & 42,2 & 248 & 57,5 \\
5 & Những câu hỏi sử dụng trong bài dạy & 111 & 25,8 & 320 & 74,2 \\
6 & Những dồ dùng dạy học liên quan trong bài & 130 & 30,2 & 301 & 69,8 \\
7 & Những khó khăn của học sinh khi học bài này & 130 & & &
\end{tabular}


Ngoài ra, khi phỏng vấn nhóm giáo viên cho biết: "Tính hợp tác của giáo viên chưa đồng bộ, các ý kiến chưa có sự thống nhất, năng lực chuyên môn của từng giáo viên chưa đồng đều, nên khó thống nhất về kế hoạch thực hiện". Bên cạnh đó, "khi đóng góp soạn giáo án chưa sâu, giáo án còn mang tính đối phó". Do đó, "Giáo viên dạy chưa thực hiện đúng thiết kế giáo án của nhóm”. Đây chính là những khó khăn của giáo viên khi soạn giáo án trong việc áp dụng NCBH.

Dự giờ, quan sát và phản hồi sau tiết dạy thử nghiệm

Kết quả khảo sát cho thấy có $375(87,01 \%) \mathrm{GV}$ trả lời trong quá trình dạy thử nghiệm, $\mathrm{GV}$ dự giờ vẫn quan sát "quá trình dạy của giáo viên". Kết quả này có thể giải thích do thói quen của giáo viên trước đây dự giờ để đánh giá giờ dạy đạt hay không đạt. Tuy nhiên, điều này trái ngược với lý thuyết về $\mathrm{NCBH}$. Theo lý thuyết về NCBH và những nghiên cứu trước đây đã cho biết: "Nhũng người quan sát có thể tập trung vào một hoc sinh gặp khó khăn với các khái niệm toán họ, một học sinh nhanh chóng tìm ra câu trả lời chính xác và trở nên chán nản." (Dudley, 2011; Lewis, Perry \& Hurd, 2004). Điều này chứng tỏ khi phản hồi sau tiết dạy thử nghiệm vẫn chưa chú ý đến quá trình học tập của người học, hay những khó khăn người học gặp phải. Thêm vào đó, các nghiên cứu trước đây cho rằng khi dự giờ quan sát, giáo viên phải tập trung năng lượng của họ vào việc học của $H S$ trong lớp và cùng nhau phát triển chuyên môn của mình trong quá trình thực hiện NCBH (Wang-Iverson et al. , 2002).

Lý thuyết về $\mathrm{NCBH}$ cho rằng việc phản hồi, suy ngẫm và rút kinh nghiệm nên được thực hiện sau khi dự giờ tiết dạy thử nghiệm xong. Theo chuyên gia Dudley, "giai đoạn phản hồi sau khi dạy thư nghiệm xong càng sớm càng tốt và chắc chắn rằng việc phản hồi không muôn hơn 24 tiếng đồng hồ" (Dudley, 2011). Tuy nhiên, kết quả khảo sát cho biết có gần phân nữa giáo viên phản hồi vào buổi sinh hoạt chuyên môn $(48,96 \%)$ và thậm chí phản hồi nhiều bài ở nhiều môn khác nhau (Huynh Thi Thuy Diem and Thathong, 2017) nên rất ít thời gian và đa số giáo viên quên là mình muốn phản hồi vấn đề nào.

Phân tích những câu trả lời của GVTHPT khi được hỏi về quá trình phản hồi, suy ngẫm của giáo viên thường tập trung những vấn đề nào thông qua những câu hỏi mở. Kết quả trả lời được mã hóa và phân chia thành các nội dung thể hiện ở Bảng 3 .

Bảng 3. Những nội dung thường được chú trọng trong phản hồi và suy ngẫm

\begin{tabular}{llc}
\hline Câu trả lời & Tổng số & Tỉ lệ \\
\hline $\begin{array}{l}\text { Các phương pháp áp dụng trong dạy học có phù hợp hay không, } \\
\text { có nâng cao được năng lực của HS hay không, có những vấn đề } \\
\text { gì cần điều chỉnh. }\end{array}$ & 77 & 17,86 \\
\hline $2 \begin{array}{l}\text { Quá trình lên lớp của GV, tổ chức lớp học và quản lí học sinh } \\
\text { trong giờ dạy của GV có bao quát lớp. }\end{array}$ & 65 & 15,08 \\
\hline $3 \quad \begin{array}{l}\text { Nội dung bài dạy có phù hợp với năng lực của HS, có đầy đủ } \\
\text { hay còn thiếu những phần nào. }\end{array}$ & 85 & 6,72 \\
\hline $\begin{array}{l}\text { Việc tiếp nhận và vận dụng kiến thức của học sinh, cách tiếp } \\
\text { nhẩn nhiệm vụ học tập vui vẻ, hay buồn chán, có phát biểu sôi } \\
\text { nồi, thảo luận nhóm tích cực hay không. }\end{array}$ & 29 & 19,72 \\
\hline $\begin{array}{l}\text { Xây dựng góp ý và bồ sung cho hoàn thiến giúp người dạy hoàn } \\
\text { thành tốt hơn: tự điều chỉnh, phương phàp dạy học, mục tiêu bài } \\
\text { học, tồ chức dạy học. }\end{array}$ & 175 & 40,6 \\
\hline Tổng cộng & 431 & 100.00 \\
\hline
\end{tabular}

Kết quả phân tích cho thấy nội dung của việc phản hồi, nhận xét sau khi dạy thử nghiệm trên lớp chiếm tỉ lệ cao nhất 40,6\% là "Xây dựng góp ý và bổ sung cho hoàn thiện giúp người dạy hoàn thành tốt hơn: tự điều chỉnh, phương pháp dạy học, mục tiêu bài học, tổ chức dạy học". Chứng tỏ việc phản hồi vẫn tập trung nhiều nhất vào người dạy và, những vấn đề khó khăn mà học sinh gặp phải, hay những buồn chán thờ ơ của học sinh khi tiếp thu kiến thức vẫn chưa được quan tâm đúng mức và ghi lại tỉ mỉ. Và buổi họp góp ý dường như không khác gì so với trước đây về mặt nội dung $(6,72 \%)$, phương pháp $(17,86 \%)$, và cách tổ chức quản lí học sinh $(15,08 \%)$. Việc góp ý nhận xét cho thấy các giáo viên trong nhóm vẫn chưa nhận ra rằng người dạy chỉ đại diện cho nhóm thực hiện kế hoạch đã đề ra trong giáo án mà nhóm đã thống nhất. Phỏng vấn một số nhóm giáo viên cho biết:

- "Góp ý sinh hoạt chuyên môn một cách chung chung, chưa cụ thể cách thực hiện, còn rất 
nhiều khó khăn trong chia sẻ kinh nghiệm soạn giảng do bất đồng ý kiến".

- "Khi rút kinh nghiệm sau tiết dạy thử nghiệm GV chưa mạnh dạn góp ý, còn nể nang trong góp ý”.

- "Giáo viên dự giờ thường phê phán người dạy không chú ý đến tương tác giữa HS với HS".

- "Còn nặng về thành tích nên đánh giá chưa sát thực tế, đóng góp tiết dạy còn rời rạc, chưa xoáy vào nội dung trọng tâm."

Kết quả nghiên cứu cho thấy chưa có ý kiến của GVTHPT cho rằng quá trình dự giờ và quan sát chính là quá trình thu thập dữ liệu, thu thập thông tin từ những gì quan sát thực tế quá trình học sinh học trên lớp. Cũng chưa có ý kiến về việc phân tích những dữ liệu thu thập được để giúp nhóm giáo viên nhìn lại kế hoạch đã lập ra có phù hợp hay không, có làm cho bài học dễ hiểu hơn không, học sinh cảm thấy thích thú với bài học hay không. Theo những nghiên cứu trước đây, trải qua một chu kỳ $\mathrm{NCBH}$, giáo viên đã học được các kỹ thuật và cách tư duy mới mà họ đã áp dụng cho tất cả việc lập kế hoạch bài học của mình. Giờ đây, họ suy nghĩ kỹ hơn về phản hồi của học sinh, thay vì chỉ lập kế hoạch để đạt được mục tiêu của bài học (Wang-Iverson et al., 2002) và như vậy họ sẽ quan sát quá trình học của học sinh kỹ hơn ( Lewis, 2002a).

\section{Thực hiện NCBH phát triển năng lực cho GVTHPT}

Kết quả khảo sát về thực tế áp dụng NCBH sẽ phát triển những năng lực nào cho GVTHPT được thể hiện ở Bảng 4 . Kết quả cho thấy giáo viên cho rằng áp dụng $\mathrm{NCBH}$ vào sinh hoạt tồ chuyên môn sẽ hỗ trợ cho GV phát triển nhũng năng lực chuyên $m o ̂ n$ chiếm tỉ lệ cao nhất $(27,61 \%)$. Tiếp theo là năng lực xủ lí nhũ̃ng tình huống thắc mắc của học sinh $(24,59 \%)$ và phát triển năng lực $t u$ duy sáng tạo

\section{Bảng 4. Thực trạng về nghiên cứu khoa học}

\begin{tabular}{lcc}
\hline Nội dung & Số lượng & Tỉ lệ phần \% \\
\hline Thuật ngữ NCKH giáo dục & & \\
\hline Đã từng nghe nói đến & 324 & 75,17 \\
Chưa từng nghe nói & 107 & 24,83 \\
\hline Làm nghiên cứu khoa học & & \\
\hline Chưa làm & 269 & 62,41 \\
Đã làm & 162 & 37,59 \\
\hline Các loại hình làm NCKH & 329 & \\
\hline Sáng kiến kinh nghiệm cá nhân & 22 & 76,33 \\
Nghiên cứu để viết một bài báo khoa học & 71 & 5,10 \\
Đề tài đại học & 64 & 16,47 \\
Đề tài cao học & 64 & 14,85 \\
Đề tài tiến sỹ & & 14,85 \\
\hline
\end{tabular}

$(23,89 \%)$. Những năng lực cần thiết mà giáo viên sẽ phát triển được khi thực hiện NCBH lại không được GVTHPT đánh giá cao trong nghiên cứu này. Kết quả khảo sát rất làm chúng ta rất ngạc nhiên và nó đi ngược lại với những nghiên cứu trước đây là GVTHPT cho rằng chỉ có $3,24 \%$ phát triển năng lưc hơp tác, 5,56\% năng lục giao tiếp và $6,26 \%$ phát triển năng lưc tư hoc và tư nghiên cứu. Kết quả này được giải thích bởi ý kiến của các GVTHPT như sau: "Các giáo viên trong tổ chuyên môn đôi lúc chura thự sự hơp tác cùng nhau xây dựng kế hoạch bài dạy, còn mang tính chất đối phó. Chỉ mang tính hình thức, hiệu quả không cao". Kết quả này được minh chứng thêm bởi kết quả khảo sát định lượng, có $66,36 \%$ GVTHPT cho rằng $\mathrm{NCBH}$ được thực hiện dạy một lần còn lại là không có dạy lần hai. Trong khi đó, nghiên cứu trước đây về việc áp dụng $\mathrm{NCBH}$ là thay đổi văn hóa trường học để cải thiện sự hợp tác, quan hệ và chia sẻ giữa các giáo viên và xem như là phương thức để nâng cao chất lượng dạy và học (Wheeler et al. 2011). Các nước trên thế giới muốn áp dụng $\mathrm{NCBH}$ vì họ mong muốn phát triển văn hóa mới trong trường học để thúc đẩy các cộng đồng học tập tại trường của họ. Đó cũng chính là lí do vì sao $\mathrm{NCBH}$ đã được áp dụng và rất phổ biết ở tất cả những nước trên thế giới (Arani et al., 2010; Fernandez \& Yoshida, 2004; Lewis, 2002; Lewis et al., 2006; Lewis \& Tsuchida, 1998; Stigler \& Hiebert, 1999). Kết quả khảo sát cho thấy $\mathrm{NCBH}$ chưa được giáo viên hiểu thấu đáo giá trị thực sự của nó.

\subsection{Thực trạng về nghiên cứu khoa học}

Kết quả khảo sát thực trạng NCKHGD của GVTHPT cho thấy trong số $431 \mathrm{GV}$ tham gia khảo sát, gần một phần tư trong số đó cho biết họ vẫn chưa từng nghe nói đến thuật ngữ NCKHGD chiếm tỉ lệ $(24,8 \%)$. Tỉ lệ $\mathrm{GV}$ đã từng làm NCKHGD là 269 GV chiếm $(62,4 \%)$ được chỉ ra trong Bảng 4. 
Trong số $431 \mathrm{GV}$ tham gia khảo sát, gần một phần tư trong số đó cho biết họ vẫn chưa từng nghe nói đến thuật ngữ NCKHGD chiếm tỉ lệ $(24,8 \%)$. Tỉ lệ $\mathrm{GV}$ đã từng làm $\mathrm{NCKH}$ là $162 \mathrm{GV}$ chiếm $(37,5 \%)$ được chỉ ra trong Bảng 4 . Nhưng khi được hỏi họ đã từng làm $\mathrm{NCKH}$ ở mức độ nào? thì có $76,3 \%$ giáo viên làm nghiên cứu khoa học là viết sáng kiến kinh nghiệm, ngược lại chỉ có $5,1 \%$ là viên có viết bài báo khoa học. Điều này chứng tỏ hoạt động làm $\mathrm{NCKH}$ của giáo viên tham gia khảo sát còn rất khiêm tốn. Sở dĩ giáo viên tham gia NCKH ở lãnh vực viết sáng kiến kinh nghiệm chiếm tỉ lệ rất cao, vì trước đây, viết sáng kiến kinh nghiệm là yêu cầu bắt buộc quy định giáo viên muốn đánh giá hoàn thành xuất sắc nhiệm vụ phải có sáng kiến kinh nghiệm (Chính phủ, 2017). Tuy nhiên, bắt đầu kể từ năm học 2018 Bộ Giáo dục và Đào tạo ban hành Thông tư 22/2018/TT-BGDĐT hướng dẫn công tác thi đua, khen thưởng ngành giáo dục thì một số tiêu chuẩn thành tích xem như thay thế sáng kiến kinh nghiệm: Tham gia soạn thảo văn bản quy phạm pháp luật, Tham gia biên soạn chương trình, tài liệu, giáo dục mầm non; chương trình, sách giáo khoa giáo dục phổ thông đã được nghiệm thu, được người có thẩm quyền xác nhận; Chủ biên 01 sách chuyên khảo được sử dụng trong giảng dạy; Chủ biên 01 giáo trình hoặc đồng chủ biên 02 giáo trình môn học được sử dụng trong giảng dạy; Tác giả chính 01 bài báo khoa học được đăng trên tạp chí chuyên ngành quốc tế nằm trong danh mục ISI hoặc Scopus (Bộ GD\&ĐT, 2018).

Bảng 5. Quan điểm của GVTHPT về mức độ quan trọng của việc thực hiện NCKHGD

\begin{tabular}{|c|c|c|c|c|c|c|}
\hline \multirow{3}{*}{ Nội dung } & \multicolumn{5}{|c|}{ Mức độ } & \multirow{3}{*}{ Mean \pm SD $\begin{array}{l}\text { Mứć độ quan } \\
\text { điềm }\end{array}$} \\
\hline & $(100 \%)$ & $(75 \%)$ & $(50 \%)$ & $(25 \%)$ & $(0 \%)$ & \\
\hline & n (\%) & n $(\%)$ & n $(\%)$ & & n $(\%)$ & \\
\hline Lựa chọn tên đề tài & 71,2 & 22,3 & 5,1 & 0,7 & 0,7 & $4,63 \pm 0,68$ Rất cần thiết \\
\hline Mục tiêu nghiên cứu & 65,7 & 27,6 & 5,3 & 0,7 & 0,7 & 4,62 $\pm 0,69$ Rất cần thiết \\
\hline Câu hỏi nghiên cứu & 46,4 & 42,7 & 8,6 & 1,6 & 0,7 & $4,32 \pm 0,76$ Cần thiết \\
\hline Giả thuyết nghiên cứu & 34,8 & 48,3 & 13,0 & 3,2 & 0,7 & $4,13 \pm 0,81$ Cần thiết \\
\hline Đặt vấn đề & 49,0 & 43,2 & 6,3 & 0,9 & 0,7 & $4,39 \pm 0,71$ Cần thiết \\
\hline Phương pháp nghiên cứu & 61,3 & 31,1 & 6,3 & 0,7 & 0,7 & $4,52 \pm 0,71$ Cần thiết \\
\hline Kết quả nghiên cứu & 59,9 & 31,8 & 6,7 & 0,7 & 0,7 & $4,49 \pm 0,72$ Cần thiết \\
\hline Bàn luận & 26,0 & 57,4 & 12,3 & 3,5 & 0,9 & $4,04 \pm 0,78$ Cần thiết \\
\hline Kết luận & 46,4 & 44,5 & 7,2 & 1,2 & 0,7 & $4,35 \pm 0,72$ Cần thiết \\
\hline Thiết kế phiếu khảo sát & 27,4 & 53,8 & 14,4 & 3,2 & 0,9 & $4,03 \pm 0,80$ Cần thiết \\
\hline Phiếu phỏng vấn & 22,3 & 48,8 & 21,6 & 6,0 & 1,2 & $3,85 \pm 0,88$ Cần thiết \\
\hline Thu thập dữ liệu & 44,7 & 46,0 & 8,1 & 0,7 & 0,7 & $4,33 \pm 0,71$ Cần thiết \\
\hline Phân tích dữ liệu & 48,0 & 42,0 & 8,1 & 1,2 & 0,7 & $4,35 \pm 0,74$ Cần thiết \\
\hline Đọc tài liệu & 45,0 & 47,6 & 5,8 & 0,9 & 0,7 & $4,35 \pm 0,70$ Cần thiết \\
\hline Xây dựng đề cương nghiên cứu & 52,2 & 37,6 & 8,4 & 1,2 & 0,7 & $4,39 \pm 0,75$ Cần thiết \\
\hline
\end{tabular}

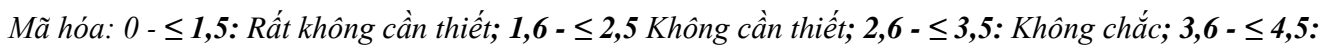

Cần thiết; 4,6 $\leq 5,0:$ Rất cần thiết

Sử dụng thang đo Likert scale 5 bậc (như mô tả ở Bảng 5) để GV tự đánh giá về "Nhũng kỹ năng và múc độ quan trọng khi thực hiện và viết báo $N C K H$ ”. Kết quả cho thấy $\mathrm{GV}$ đánh giá ở mức độ Rất cần thiết $(\mathrm{M}=4,63 \pm 0,68)$ đối với kỹ năng "Lựa chọn tên đề tài" và $(M=4,62 \pm 0,69)$ và kỹ năng xác định "Mục tiêu nghiên cứu". Theo Nguyễn Văn Tuấn (2013) thì tựa bài báo đóng vai trò quan trọng trong việc thu hút sự chú ý và các chuyên gia phản biện. Với nhà nghiên cứu khác cũng cho rằng việc xác định một vấn đề nghiên cứu không phải là một việc làm đơn giản và đôi khi còn khó hơn việc giải quyết vấn đề đó (Nguyễn Văn Tuấn, 2007). Trong khi đó, mục tiêu nghiên cứu cũng được các đối tượng xếp ở mức rất cần thiết khi thực hiện và viết báo NCKH. Kết quả nghiên cứu này cũng tương đồng với những nhà nghiên cứu khác viết mục tiêu nghiên cứu rất cần thiết bởi vì nó có tính chất quyết định cho việc nghiên cứu tiếp theo hay giá trị của kết quả nghiên cứu. Thật vậy, theo Nguyễn Văn Tuấn (2013), viết mục tiêu nghiên cứu có hai khía cạnh: mục tiêu của viết đề cương nghiên cứu là thuyết phục vụ nhà tài trợ hay hội đồng xét duyệt và mục tiêu của viết bài báo khoa học là để báo cáo những phát hiện cụ thể trong một nghiên cứu và nó có ý nghĩa gì. Còn theo Nguyễn Văn Tuấn (2007), 
mục tiêu là cái đích mà người nghiên cứu vạch ra để thực hiện và nỗ lực nghiên cứu để đạt đến kết quả cuối cùng.

Tất cả những kỹ năng còn lại GVTHPT cho rằng ở mức độ cần thiết. Trong đó, kỹ năng phương pháp nghiên cứu có độ lệch chuẩn trung bình cao hơn các kỹ năng còn lại $(\mathrm{M}=4,52 \pm 0,71)$ và thấp nhất là kỹ năng thiết kế phiếu phỏng vấn $(\mathrm{M}=3,85 \pm 0,88)$. Điều này cho thấy GVTHPT gặp khó khăn rất nhiều trong việc xác định phương pháp nghiên cứu.

\subsection{Các giải pháp đẩy mạnh hoạt động NCBH và NCKHGD của GVTHPT}

Đẩy mạnh hoạt động NCBH và NCKHGD cho GVTHPT có 7 giải pháp được các GVTHPT chia sẻ, trong đó có hai giải pháp cao nhất là: "Các cấp lãnh đạo trong nhà trường tạo điều kiện cho giáo viên có nhiều cơ hội được học tập bồi dưỡng nhiều hơn về NCBH và NCKHGD" chiếm $27,84 \%$ và "Cần có sự giúp đỡ, hướng dẫn của người có kinh nghiệm và phải được chuyên gia đầu ngành ở truờng đại hoc về tập huấn hàng năm. Tổ chức tọa đàm trao đổi kinh nghiệm, hố trợ tháo gỡ nhũng khó khăn cho $G V$ về NCBH và NCKHGD" chiếm 27,61\%. Kết quả này cho thấy GVTHPT còn hạn chế về những kiến thức và kỹ năng $\mathrm{NCBH}$ và $\mathrm{NCKHGD} \mathrm{và} \mathrm{họ} \mathrm{mong}$ muốn được học hỏi và phát triển. Bởi vì $\mathrm{NCBH}$ và NCKHGD sẽ giúp GVTHPT không những phát triển những năng lực chung (giao tiếp, hợp tác, tự học, tư duy sáng tạo) mà còn phát triển những năng lực chuyên biệt (tìm hiểu sâu hợn về kiến thức chuyên môn và nghiệp vụ sư phạm).

\section{KẾT LUẬN}

Việc áp dụng NCBH vào sinh hoạt tổ chuyên môn đã được Bộ GD\&ĐT chỉ đạo thực hiện rộng rãi với mọi môn học và mọi cấp học từ mầm non đến Tiểu học, đến Trung học Cơ sở và Trung học Phổ thông thực hiện cách nay hơn sáu năm. Tuy nhiên, $\mathrm{NCBH}$ vẫn chưa được GVTHPT hiểu đúng đắn, đầy đủ ý nghĩa khi thực hiện, nên GVTHPT vẫn chưa thấy được hết giá trị và lợi ích sâu xa của việc áp dụng NCBH vào sinh hoạt tổ chuyên môn. Vì vậy, cần có một phương pháp tập huấn tích cực, thực tế về NCBH để giúp GVTHPT hiểu thấu đáo và cặn kẻ NCBH. Bên cạnh đó, kết quả khảo sát hoạt động nghiên cứu khoa học đặc biệt là NCKHGD của GVTHPT đã cho thấy đây là hoạt động rất yếu ở trường Trung học Phổ thông. Vì vậy để đẩy mạnh việc $\mathrm{NCBH}$ và $\mathrm{NCKH}$ cho GVTHPT, nhà trường cần phải có những giải pháp cụ thể như mời các chuyên gia của trường đại học về $\mathrm{NCBH}$ đến tập huấn, hướng dẫn, hỗ trợ và cùng với GVTHPT thực hiện trên lớp học thực tế thường xuyên. Có như vậy thì việc áp dụng $\mathrm{NCBH}$ vào sinh hoạt tổ chuyên môn mới hiệu quả và mới phát triển năng lực NCKHGD cho GVTHPT.

\section{TÀI LIỆU THAM KHẢO}

Arani, Reza, M., Keisuke, F., and Lassegard, J. P. (2010). "Lesson study" as professional culture in Japanese schools: An historical perspective on elementary classroom practices. Japan Review, 22, 171-200. https://doi.org/10.1016/B978012373990-2.00002-9

Ban Chấp hành Trung ương. (2013). Nghị Quyết số 29-NQ/TW ngày 04 tháng 11 năm 2013 (trang 12).

Bộ Giáo dục và Đào tạo. (2014a). Công văn hưóng dẫn thưc hiện nhiệm vụ Giáo dục trung học năm hoc 2014-2015 (pp. 1-9).

Bộ Giáo dục và Đào tạo. (2014b). Công văn hướng dẫn sinh hoạt chuyên môn về đổi mới phương pháp dạy học và kiểm tra, đánh giá; tổ chức và quản lý các hoạt động chuyên môn của trường trung học/trung tâm giáo dục thường xuyên qua mạng (Số 5555/BGDĐT-GDTrH) (trang 1-5).

Bộ Giáo dục và Đào tạo. (2018). Thông tư Hướng dẫn công tác thi đua, khen thưởng ngành Giáo dục (Số 22/2018/TT-BGDĐ) (trang 15).

Bui Lan Chi, Phung Thi Nguyet Hong, Wheeler, C. W., Lai Thi Cam and Ho Thi Thu Ho. (2008). Lesson study in 7th grade lower secondary mathematics classes: What teachers learned about student learning*. WALS 2008 Conference, December 1st3rd, 2008. Hong Kong, China, 1-27.

Bui Lan chi, Wheeler, C. W., Phung thi Nguyet Hong, Trinh Quoc Lap and Ho Thi Thu Ho. (2008). The Impact of the CTU-MSU project on grade level and department teams in project schools *. WALS 2008 Conference, December 1st-3rd, 2008. Hong Kong, China, (May 2001), $1-20$.

Cheng, E. (2011). How lesson study develops preservice teacher' instructional design competency? The International Journal of Research and Review, 7(1), 45-66.

Chokshi, S. and Fernandez, C. (2004). Challenges to importing Japanese lesson study: Concerns, misconceptions, and nuances. Phi Delta Kappan, 85(7), 502.

https://doi.org/https://doi.org/10.1177/00317217 0408500710

Chong, W. H. and Kong, C. A. (2012). Teacher collaborative learning and teacher self-efficacy: The case of lesson study. The Journal of Experimental Education, 80(3), 263-283. https://doi.org/10.1080/00220973.2011.596854

Cohen, L., Manion, L. and Morrison, K. (2007). Research Methods in Education. In Routledge, 
London and New York. https://doi.org/10.1080/19415257.2011.643130

Đào Ngọc Cảnh. (2018). Thực trạng và giải pháp đẩy mạnh hoạt động nghiên cứu khoa học của giảng viên Trường Đại hoc Cần Thơ. Tạp chi Khoa học Truờng Đại học Cần Tho, 54(7), 117-121.

Dudley, P. (2011). Lesson study: a handbook. In Lesson study UK.

Fernandez, C. (2002). Learning from Japanese Approaches to Professional Development: The Case of Lesson Study. Journal of Teacher Education, 53, 393-405. https://doi.org/10.1177/002248702237394

Fernandez, C. and Yoshida, M. (2004). Lesson study a Japanese approach to improving mathematics teaching and learning. Lawrence Erlbaum Associates, Inc.

Glase, B. G. and Strauss, A. L. (1967). The discovery of grounded theory: strategies for qualitative research. In Statewide Agricultural Land Use Baseline. https://doi.org/10.1017/CBO9781107415324.004

Ho Thi Thu Ho, Phung Thi Nguyet Hong, Wheeler, C. W. and Bui Lan Chi. (2008). Lesson study in 5 th grade primary school geography: What teachers learned about content and student skill levels. Paper for Presentation at WALS 2008 Conference, December 1st-3rd, 2008. Hong Kong, China, 1-18.

Ho Thu Thu Ho, Trinh Quoc Lap and Nguyen Thi Hong Nam. (2012). Applying lesson study in micro-teaching for teacher education in a Vietnamese context. Case study in a Geography micro-teaching course in Can Tho UniversityVietnam. The World Association of Lesson Study (WALS) 2012 International Conference, November 28-30, in Singapore.

Ho Thi Thu Ho, Wheeler, C. W., Bui Lan Chi and Phung Thi Nguyet Hong. (2009). Organizational support for teacher development: Improving the function of grade level and department teams. Paper for Presentation at WALS 2009 Conference, December 7th - 10th, 2009. Hong Kong, China., 1-22.

Huynh Thi Thuy Diem and Thathong, K. (2017). Applying lesson study among high school biology teacher Vietnam. International Journal of Educational Science and Research, 7(4), 7-18.

Inprasitha, M. (2011). One Feature of Adaptive Lesson Study in Thailand: Designing a Learning Unit. Journal of Science and Mathematics Education in Southeast Asia, 34(1), 47-66.

Krejcie, R. V and Morgan, D. W. (1970). Determining sample size for research. Educational and Psychological Measurement, 30, 607-610.
Lewis, C. (2000). Lesson study: The core of Japanese professional development. In Annual Meeting of the American Educational Research Association New Orleans LA. http://www.lessonresearch.net/aera2000.pdf

Lewis, C. C. (2002a). Brief guide to lesson study. Philadelphia: Research for Better Schools, 135.

Lewis, C. C. (2002b). The Teaching Gap. 1999, 1-5.

Lewis, C., Perry, R. and Hurd, J. (2004). A deeper look at lesson study. Educational Leadership, 61(5), 18-22.

Lewis, C., Perry, R. and Murata, A. (2006). How should research contribute to instructional inprovement? The case of lesson study. Educational Researcher, 35, 3-14. https://doi.org/10.3102/0013189X035003003

Lewis, C. and Tsuchida, I. (1998). A lesson is like a swiftly flowing river how research lessons improve Japanese education. America Educator, 12-17, 50-51.

Lieberman, J. (2009). Using Lesson Study to Develop an Appreciation of and Competence in Task Design.

Likert, R. (1932). A technique for measurement of attitudes. Archives of Psychology, 140, 5-55.

Lim, C., Lee, C., Saito, E. and Syed Haron, S. (2011). Taking stock of lesson study as a platform for teacher development in Singapore. Asia-Pacific Journal of Teacher Education, 39(4), 353-365. https://doi.org/10.1080/1359866X.2011.614683

Makinae, N. (2010). The origin of lesson study in Japan. The Organizers of the EARCOME5, Japan Society of Mathematical Education, 8.

Meng, C. C. and Sam, L. C. (2011). Encouraging the innovative use of geometer's sketchpad through lesson study. Creative Education, 2(3), 236-243. https://doi.org/10.4236/ce.2011.23032

Chính phủ. (2017). Nghị định về đánh giá và phân loại cán bộ, công chưc, viên chưc (Số 88/2017/NĐ-CP).

Nguyễn Văn Tuấn. (2007). Giáo trình phưong pháp nghiên cúu khoa hoc giáo duc. Trường Đại học Sư phạm Kỹ thuật thành phố Hồ Chí Minh.

Nguyễn Văn Tuấn. (2013). Tù nghiên cứu đến công bố-Kỹ năng mềm cho nhà khoa học. Nhà xuất bản tổng hợp Thành Phố Hồ Chí Minh.

Saito, E., Khong Thi Diem Hang \& Tsukui, A. (2012). Why is school reform sustained even after a project? A case study of Bac Giang Province, Vietnam. Journal of Educational Change, 13, 259-287. https://doi.org/10.1007/s10833-011-9173-y

Saito, E., Tsukui, A. \& Tanaka, Y. (2008). Problems on primary school-based in-service training in Vietnam: A case study of Bac Giang province. 
International Journal of Educational Development, 28(1), 89-103. https://doi.org/10.1016/j.ijedudev.2007.08.001

Sở Giáo dục và Đào tạo thành phố Cần Thơ. (2014). Hương dẫn chi thị thực hiện nhiệm vu giáo dục trung hoc năm họ 2014-2015 (trang 18-30).

Stigler, W. J. and Hiebert, J. (1999). The teaching gap: Best ideas from world's teacher for improving education in the classroom.

Suratno, T. (2012). Lesson study in Indonesia: an Indonesia University of Education experience. International Journal for Lesson and Learning Studies, 1, 196-215. https://doi.org/10.1108/20468251211256410

Tan-Chia, L., Fang, Y. and Ang, P. C. (2013). Innovating the Singapore english language curriculum through lesson study. International Journal for Lesson and Learning Studies, 2, 256-280. https://doi.org/10.1108/IJLLS-032013-0017
Tran Vui. (2006). Enhancing classroom communication to develop students' mathematical thinking. Tsukuba Journal of Educational St Udy in Mathematics, 25, 279-287.

Tran Vui. (2013). Lesson tsudy for good practices in teaching and learning mathematics in Vietnam. The International Journal of Educational Administration and Development, 4(2), 757-765.

Trọng Hoàng \& Chu Nguyễn Mộng Ngọc. (2008). Phân tích dũ liệu nghiên cúu với SPSS.

Wang-Iverson, P., Buckwalter, W., \& Sanchez, C. (2002). What is Lesson Study. Research for Better School, 5(2), 2-16.

Wheeler, C. W., Bui Lan Chi, Phung Thi Nguyet Hong and Ho Thi Thu Ho. (2011). Lesson study in Vietnam: A country report. The 23rd UNESCO-APEID Hiroshima Seminar on Innovation and Reform in Teacher Education in the Asia-Pacific Region, 1-15. 